Selcuk Journal of Agriculture and Food Sciences

http://sjafs.selcuk.edu.tr/sjafs/index

Research Article
SJAFS

(2021) 35 (3), 244-248

e-ISSN: $2458-8377$

DOI:10.15316/SJAFS.2021.253

\title{
The Effects of Nitrogen Protoxide and Orizalin on Promotion of Polyploidy in Grapes
}

iD Zeki KARA ${ }^{1, *}$, ID Mine ERBOĞA ${ }^{2}$, ID Osman DOĞAN ${ }^{1}$

${ }^{1}$ Selçuk University, Faculty of Agriculture, Department of Horticulture, Konya, Turkey

${ }^{2}$ Selçuk University, Institute of Science, Department of Horticulture, Konya, Turkey

\begin{tabular}{l}
\hline ARTICLE INFO \\
\hline Article history: \\
Received date: 25.10 .2011 \\
Accepted date: 02.11 .2021 \\
\hline
\end{tabular}

Keywords:

Grapevine

Breeding

Poiploidy

Nitrous protoxide

Oryzalin

\begin{abstract}
The effort to reach higher yield and quality in grape production without losing the current quality has led researchers to induce polyploidy with chemical mutagens that cause less damage to the environment and researchers to obtain polyploid grape genotypes. The fact that the number of polyploid grape varieties and their production continue to increase creates synergy for research in this direction. In this study, Nitrous Protoxide, Oryzalin and their combined applications were tested to induce polyploidy in seeds and seedlings whose germination was exponentially induced of cvs. Ekşi Kara and Gök Üzüm (both Vitis vinifera $\mathrm{L}$.). After $48-\mathrm{h}, \mathrm{N}_{2} \mathrm{O}$ at 5 bar pressure was applied to seeds that germinated until root tips were visible, as well as 48-h and/or 96-h 0 (control), $25 \mu \mathrm{M}$ and $100 \mu \mathrm{M}$ oryzalin were applied to seedlings whose cotyledon leaves reached full size. Ploidy verification was made by flow cytometry (FC) analysis in selected seedlings by examining the effects of the treatments on the surviving seedling rate, stoma density and size, and the number of chloroplasts. While the morphological and cytological effects of all mutagen applications were found to be significant, only one seedling selected from $25 \mu \mathrm{M} 48$-h oryzalin application in Ekşi Kara cultivar was confirmed by FC analysis. Plant survival rate was lower and morphological differences were more pronounced in the combination of $\mathrm{N}_{2} \mathrm{O}$ and oryzalin. In future studies, more polyploid induction can be tried with different dose and application time combinations of $\mathrm{N}_{2} \mathrm{O}$ and oryzalin.
\end{abstract}

\section{Introduction}

In the grape marketing sector, it is important to develop high quality grape varieties with good market value. In grape breeding, it is aimed to develop varieties that can adapt well to different conditions, have high stress tolerance, good yield, and quality characteristics. Stimulated polyploidization technique is a widely used in plant breeding, as it provides various morphological differences in plant growth and development and generally strong environmental adaptation (Esmaeili et al 2020; Wang et al 2020). Although colchicine is effective in autopolyploid induction in vine, it has been sought for alternative mutagens due to its intensive labour requirement, dangerous and high price of higher concentrations (Kihara \& Tsunewaki, 1960; Kitamura et al 2009), chimera regeneration, formation of aneuploids, abnormalities in plant development, and low seed productivity (Hassawi \& Liang, 1991).

Compounds such as dinitroaniline and phosphonodiamidite have been used in polyploidization

\footnotetext{
*Corresponding author email: zkara@selcuk.edu.tr
}

studies in recent years (Ramulu et al 1991; Tosca et al 1995; Hansen \& Andersen, 1996; Väinölä, 2000; Simmonds et al 2001; Kermani et al 2003; Eeckhaut et al 2004; Pintos et al 2007; Touchell et al 2020). When colchicine, APM and different dinitroanilines (oryzalin, ethalfluralin, trifluralin, pendimethalin, benefin) were compared, a higher polyploidization potential was determined for all dinitroanilines compared to colchicine (Mitrofanova et al 2003).

Antimicrotubular herbicides were thought to be alternatives since they inhibit microtubule in a similar way to colchicine (Yemets \& Blume, 2008). It has been reported in different species that nitrous oxide $\left(\mathrm{N}_{2} \mathrm{O}\right)$ gas is effective in the doubling of the chromosome number in the cell and the formation of polyploid genotypes by preventing the formation of spindle fibbers and the retraction of chromosomes during the cell division process (Kihara \& Tsunewaki, 1960; Kitamura et al 2009).

In this study, the effects of combined and separate applications of Nitrous Oxide $\left(\mathrm{N}_{2} \mathrm{O}\right)$ and Oryzalin on ploidy promotion in cvs. Ekşi Kara and Gök Üzüm (both Vitis vinifera L.) were investigated at the morphological and cytological phase. 


\section{Materials and Methods}

As the plant material, seeds of cvs. Ekşi Kara and Gök Üzüm which are the most important cultivars of vineyards in the Central Taurus Mountains, were germinated after 90 days of stratification at $+4{ }^{\circ} \mathrm{C}$ and their root tips became visible. Tetraploid (4x) 'Kyoho' was used as control.

The application doses and durations of Nitrous oxide $\left(\mathrm{N}_{2} \mathrm{O}\right)$ and Oryzalin as chemical mutagens are presented in Table 1.

In the experiment of induction of polyploidy with $\mathrm{N}_{2} \mathrm{O}$, germinated seeds applied $0,48-\mathrm{h}$ and 96-h $\mathrm{N}_{2} \mathrm{O}$ under 5 bar pressures were sown in production pans in the greenhouse. In the trial of polyploidy induction with oryzalin, two application times (0 (control), 48-h and 96-h), two doses of oryzalin [0 (control), $25 \mu \mathrm{M}$ and $100 \mu \mathrm{M}]$ were applied to the seedlings that reached the cotyledon stage. Pure water was applied to control seedlings.

The experiment was set up in a randomized block design with 3 replications, and the number of plants in each replication was 12 . In total, morphological, and cytological observations were made on 720 seedlings.

The rate of conversion to plant was calculated by dividing the number of shoot tips applied and viable to the total number of plants. Shoot length was measured Table 1 Effects on morphological traits on mutagen treated seedlings with a tape measure at the end of vegetation. The width and length of the stoma were examined with a $40 \mathrm{x}$ magnification objective binocular microscope by peeling the lower epidermis of the leaf and placing it on the slide. In addition, chloroplasts were counted in all seedlings and compared with tetraploid (4x) 'Kyoho' grape variety. Flow cytometry (FC) analysis was performed on the selected material by determining the morphological difference. Data were subjected to analysis of variance (ANOVA), means were compared with Duncan multiple comparison test.

\section{Results and Discussion}

According to the results obtained from the multivariate analysis, the viability rate $(\%)$, shoot length $(\mathrm{cm})$, stomatal density (number stoma $\mathrm{mm}^{-2}$ ) and stomatal size $(\mu \mathrm{m})$ of the examined traits in seedlings treated with $\mathrm{N}_{2} \mathrm{O}$ and oryzalin were significantly higher than chemical mutagen applications $(\mathrm{p}<0.01)$. affected (Table 1). The shoot length difference between the two grape cultivars treated with mutagen was significant $(p<0.01)$. Viability rates were affected by the increase in application time $(\mathrm{p}<0.01)$. Stoma densities (number stoma $\left.\mathrm{mm}^{-2}\right)$ were significantly affected $(\mathrm{p}<0.01)$ according to cultivar, mutagen doses and application times (Table 1 and Table 2).

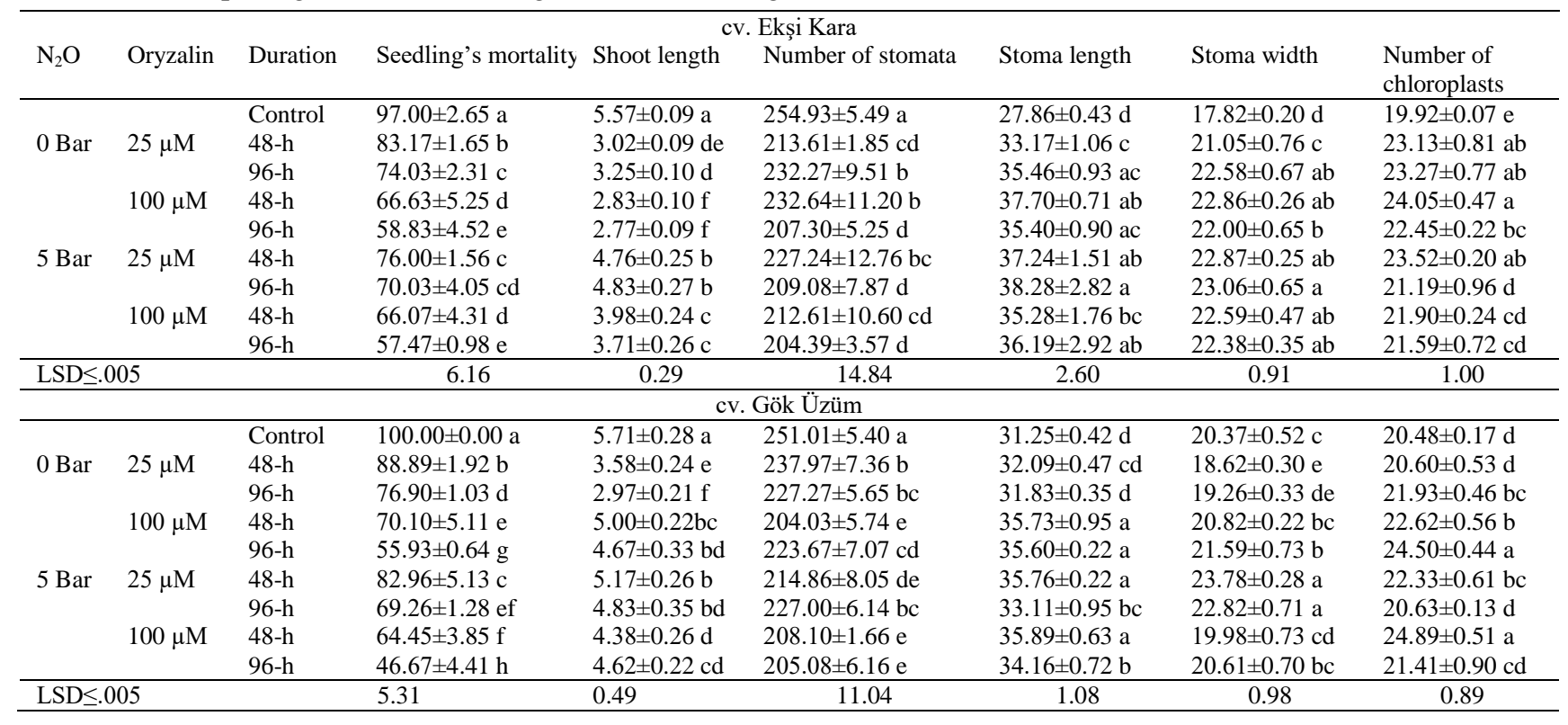

\subsection{Vitality Rate (\%)}

The viability rate of the plants treated with oryzalin and/or $\mathrm{N}_{2} \mathrm{O}$ decreased $(\mathrm{p}<0.05)$. In the Oryzalin study, increasing doses and application times decreased the surviving plant rate. The viability rate of seedlings treated with $\mathrm{N}_{2} \mathrm{O}$ was higher than those treated with Oryzalin. In cv. Ekşi Kara, the highest rate of viability was obtained in the control $(85 \pm 1.73 \%)$, while the highest seedling death was in the application of 5 bar- 48-h $\mathrm{N}_{2} \mathrm{O}+100 \mu \mathrm{M} 96-\mathrm{h}$ oryzalin $(57.47 \pm 0.98 \%$ survival).

The highest survival rate in cv. Gök Üzüm was determined in the control $(90 \pm 2 \%)$ and the lowest $(46.67 \% \pm 4.40) 5$ bar $48-\mathrm{h} \mathrm{N}_{2} \mathrm{O}+100 \mu \mathrm{M} 96$-h oryzalin application (Table 1 and Table 2).

In a previous study using oryzalin in artificial induction of polyploidy in grapevine, the survival rates of 
autotetraploid plants ranged from 8.6 to $30 \%$, depending on the variety (Bosco et al 2017). In another study of chromosomal folding in grapevine, while the linear effect of oryzalin on plant survival was determined, it was determined that increasing doses of oryzalin were more effective on plant regeneration than the application time (Sinski et al 2014). Similarly, $120 \mu \mathrm{M} 24-\mathrm{s}$ (33\% of surviving explants were tetraploid) was reported to be the most effective of the in vitro applied Table 2

The ANOVA of seedlings differences that treated with $\mathrm{N}_{2} \mathrm{O}$ and oryzalin

\begin{tabular}{|c|c|c|c|c|c|c|c|}
\hline SV & $d f$ & $\begin{array}{l}\text { Seedling's mor- } \\
\text { tality }\end{array}$ & Shoot length & $\begin{array}{l}\text { Number of sto- } \\
\text { mata }\end{array}$ & Stoma length & Stoma width & $\begin{array}{l}\text { Number of } \\
\text { chloroplasts }\end{array}$ \\
\hline Cultivar & 1 & $44.374^{\mathrm{ns}}$ & $4.647^{* *}$ & $0.077^{\mathrm{ns}}$ & $0.053^{\mathrm{ns}}$ & $3.480^{*}$ & $1.188^{\mathrm{ns}}$ \\
\hline Dosage & 3 & $1252.006^{\text {*** }}$ & $2.411^{* *}$ & $774.881^{* *}$ & $29.165^{* *}$ & $23.026^{*}$ & $3.442^{* *}$ \\
\hline Duration & 1 & $1109.673^{* *}$ & $0.058^{\mathrm{ns}}$ & $56.587^{\mathrm{ns}}$ & $1.364^{\mathrm{ns}}$ & $0.551^{\mathrm{ns}}$ & $6.538^{* *}$ \\
\hline Cul. x Dos. & 1 & $24.160^{\mathrm{ns}}$ & $5.368^{* *}$ & $374.270^{*}$ & $4.043^{\mathrm{ns}}$ & $4.076^{*}$ & $7.583^{* *}$ \\
\hline Cul. x Dur. & 1 & $31.924^{\mathrm{ns}}$ & $0.468^{*}$ & $91.650^{\mathrm{ns}}$ & $0.189^{\mathrm{ns}}$ & $0.204^{\mathrm{ns}}$ & $8.178^{* *}$ \\
\hline Dos. x Dur. & 3 & $7.357^{\mathrm{ns}}$ & $0.113^{\mathrm{ns}}$ & $78.300^{\mathrm{ns}}$ & $3.007^{\mathrm{ns}}$ & $1.245^{\mathrm{ns}}$ & $8.631^{* *}$ \\
\hline Cul.xDos.xDur. & 1 & $4.646^{\mathrm{ns}}$ & $0.125^{\mathrm{ns}}$ & $2072.711^{\text {** }}$ & $7.205^{\mathrm{ns}}$ & $2.388^{\mathrm{ns}}$ & $1.955^{\mathrm{ns}}$ \\
\hline Failure & 40 & 16.062 & 0.313 & 162.343 & 6.414 & 4.207 & 4.792 \\
\hline
\end{tabular}

ns: Not significant, *: Significance level 5\%, **: Significance level 1\%, Cul : Cultivar, Dos.: Dosage, Dur.: Duration, SV: Source of variation,

$d f$ : Degree of freedom

\subsection{Shoot Length}

The effects of mutagen treatments on shoot length were significant $(\mathrm{p}<0.05)$. Although less in $\mathrm{N}_{2} \mathrm{O}$ applied plants; Increasing mutagen dose and application times caused a decrease in shoot length. While the shoot length was $5.57 \pm 0.09 \mathrm{~cm}$ in cv. Ekşi Kara control seedling, the lowest shoot length was $2.77 \pm 0.09$ $\mathrm{cm}$ in $100 \mu \mathrm{M} 96-\mathrm{h}$ oryzalin treated seedlings. The shoot length was $5.71 \pm 0.28 \mathrm{~cm}$ in the control seedlings of cv. Gök Üzüm, and the lowest shoot length was $2.96 \pm 0.50 \mathrm{~cm}$ in those treated with $25 \mu \mathrm{M} 96-\mathrm{h}$ oryzalin (Table 1 and Table 2).

In previous studies of chromosome folding in grapevine in vitro, significant delays in growth and development of explants were reported (Xie et al 2015). Moreover, autotetraploid plants obtained from artificial polyploidy stimulation with in vitro oryzalin in grapevine had shorter internodes, thicker stems and more compact root systems (Sinski et al 2014).

\subsection{Stoma Data}

The effects of mutagen applications on stomatal length, width and density were significant $(\mathrm{p}<0.05)$. All applications increased the stoma length and width. In cv. Ekşi Kara, stomatal length was $27.86 \pm 0.43 \mu \mathrm{m}$ in control seedlings; It was measured as $38.28 \pm 2.82 \mu \mathrm{m}$ in the application of 5 bar $\mathrm{N}_{2} \mathrm{O}+25 \mu \mathrm{M}$ 96-h oryzalin. The stomatal length was $31.24 \pm 2.20 \mu \mathrm{m}$ in the control $2.64 \mu \mathrm{m}$ in those treated with 5 bar $\mathrm{N}_{2} \mathrm{O}+100 \mu \mathrm{M} 48-\mathrm{h}$ oryzalin. While the stomatal width of cv. Ekşi Kara control seedlings was $17.82 \pm 0.20 \mu \mathrm{m}$; The largest stomata were $23.06 \pm 1.14 \mu \mathrm{m}$ with 5 bar $\mathrm{N}_{2} \mathrm{O}+25 \mu \mathrm{M}$ 96-h oryzalin applied plants. While the stomatal width was measured as $20.36 \pm 1.47 \mu \mathrm{m}$ in the control seedlings of the cv. Gök Üzüm; The largest stomata were in seedlings treated with $23.78 \pm 0.81 \mu \mathrm{m}$ and 5 bar $\mathrm{N}_{2} \mathrm{O}$ $+25 \mu \mathrm{M} 48$-h oryzalin (Table 1 and Table 2 ). seedlings of the cv. Gök Üzüm, while it was $36.55 \pm$ 2008). In addition, it has been suggested that the dose and application times that reduce the plant survival rate may provide an advantage by reducing the number of diploid and mixoploid plants. It was also reported that tetraploid plants obtained with high mutagen doses could show abnormalities such as a decrease in growth rate (Väinölä \& Repo, 2000). oryzalin doses in Watsonia lepida (Ascough et al

All mutagen applications reduced stoma density. In cv. Ekşi Kara, the densest stoma was $254.93 \pm 14.81$ $\mathrm{mm}^{-2}$ in the control, the least stoma was $204.39 \pm 3.57$ $\mathrm{mm}^{-2}$ in 5 bar $\mathrm{N}_{2} \mathrm{O}+100 \mu \mathrm{M} 96-\mathrm{h}$ oryzalin application. In cv. Gök Üzüm, the highest stomatal density was $251.008 \pm 13.54 \mathrm{~mm}^{-2}$ in control seedlings, and the minimum $204.02 \pm 5.73 \mathrm{~mm}^{-2}$ in $100 \mu \mathrm{M} 48$-h oryzalin application.

In a similar previous study, the stomatal length of tetraploid plants was one-third longer than diploids (Xie et al 2015). In another grapevine polyploidy study, researchers reported that the stomatal length and width values of the tetraploid plants they obtained showed a positive correlation with the chromosome numbers and a negative correlation with the stomatal density (Sinski et al 2014).

\subsection{Chloroplast Count Data}

Both mutagen treatments increased chloroplast numbers significantly $(\mathrm{p}<0.05)$ in seedlings of both grape cultivars. In cv. Ekşi Kara, $19.92 \pm 0.07$ chloroplasts per cell were determined in control seedlings, while the maximum number of chloroplasts was 24.05 \pm 0.47 in $100 \mu \mathrm{M}+48$-h oryzalin applied seedlings. The number of chloroplasts per cell in cv. Gök Üzüm ranged from $20.48 \pm 0.16$ units in control seedlings to $24.88 \pm 7.32$ units in the application of 5 bar $\mathrm{N}_{2} \mathrm{O}+$ $100 \mu \mathrm{M} 48$-h oryzalin (Table 1 and Table 2).

In a previous study, it was reported that the number of chloroplasts in stomatal guard cells was determined as $14.4 \pm 1.81$ in diploids and $23.5 \pm 1.78$ in tetraploids, as an effective and economic indicator for distinguishing tetraploids (Xie et al 2015). Other previous studies have suggested that stomatal size measurement and chloroplast count in stomatal guard cells are the most economical and efficient methods for detecting polyploidy (de Carvalho et al 2005; Yang et al 2006). In addition, it has been reported that chloroplast densities in stomatal guard cells are directly proportional to the 
number of chromosomes (Sinski et al 2014; Lan et al 2020). In the polyploid induction made in Alocasia plant, the best result was obtained with a 24-hour application of $0.01 \%$ oryzalin, with a rate of $15.4 \%$ tetraploid plant (Thao et al 2003).

\subsection{Flow Cytometry (FC) Analysis}

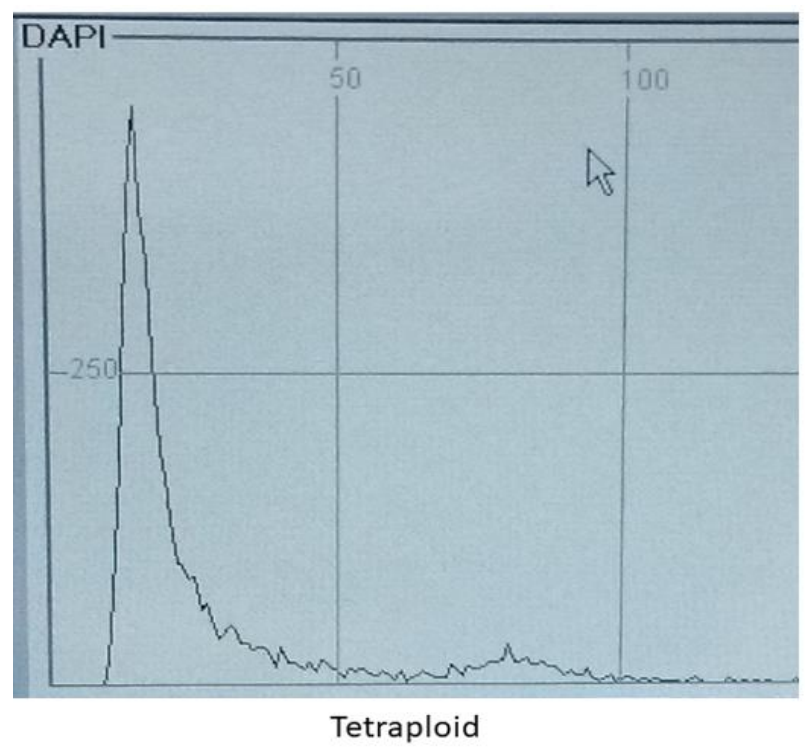

Morphological differences were determined by all observations, and seedlings suspected of being polyploid were selected and flow cytometry analysis was performed on them. Selected 1 Ekşi Kara seedling treated with $25 \mu \mathrm{M} 48$-h oryzalin was confirmed to be tetraploid (Figure 1).

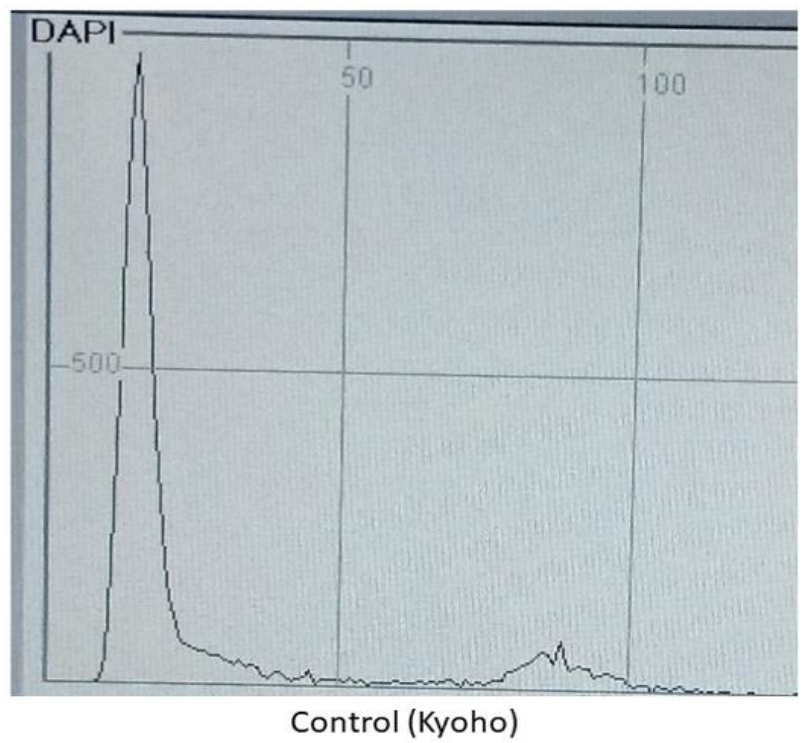

Figure 1

FC histograms of selected tetraploid cv. Ekşi Kara seedling (left) and tetraploid cv. Kyoho (right)

\section{Conclusion}

Our study is the first report in which $\mathrm{N}_{2} \mathrm{O}$ and oryzalin were used together to obtain polyploidy in grapevine in vivo. By the $\mathrm{N}_{2} \mathrm{O}$ and Oryzalin and combined mutagen applications, significant changes were recorded in morphological analyses in all the seedlings that survived and developed. In combination with $\mathrm{N}_{2} \mathrm{O}$ + oryzalin, plant survival rate was lower and morphological differences were more pronounced. It was confirmed that changes in stomatal density and size, and changes in the number of chloroplasts could be used in the preselection of polyploidy prior to flow cytometry. In future studies, more polyploid induction can be tried with different dose and administration time combinations of $\mathrm{N}_{2} \mathrm{O}$ and oryzalin. All surviving plants in our study are being preserved and monitored.

\section{Acknowledgements}

This study was supported by the Scientific Research Projects Coordinatorship of Selçuk University as the thesis project numbered 19201084 .

\section{References}

Ascough GD, Van Staden J, Erwin JE (2008). Effectiveness of colchicine and oryzalin at inducing polyploidy in Watsonia lepida NE Brown, HortScience, 43 (7): 2248-2251.
Bosco D, Sinski I, Maia J, Ritschel P, Quecini V (2017). Artificially induced autopolyploidy increases genome-wide methylation in grapevine, Embrapa Uva e Vinho-Resumo em anais de congresso (Alice).

de Carvalho JFRP, de Carvalho CRdP, Otoni WC (2005). In vitro induction of polyploidy in annatto (Bixa orellana), Plant cell, tissue organ culture, 80 (1): 69-75.

Eeckhaut TG, Werbrouck SP, Leus LW, Van Bockstaele EJ, Debergh PC (2004). Chemically induced polyploidization in Spathiphyllum wallisii Regel through somatic embryogenesis, Plant cell, tissue organ culture, 78 (3): 241-246.

Esmaeili G, Van Laere K, Muylle H, Leus L, (2020). Artificial Chromosome Doubling in Allotetraploid Calendula officinalis, Frontiers in Plant Science, 11,622 .

Hansen N, Andersen SB (1996). In vitro chromosome doubling potential of colchicine, oryzalin, trifluralin, and APM in Brassica napus microspore culture, Euphytica, 88 (2): 159-164.

Hassawi DS, Liang GH (1991). Antimitotic agents: effects on double haploid production in wheat, Crop science, 31 (3): 723-726.

Kermani M, Sarasan V, Roberts A, Yokoya K, Wentworth J, Sieber V (2003). Oryzalin-induced chromosome doubling in Rosa and its effect on plant morphology and pollen viability, Theoretical Applied Genetics, 107 (7): 1195-1200. 
Kihara H, Tsunewaki K (1960). Production of polyploid wheat by nitrous oxide, Proceedings of the Japan Academy, 36 (10): 658-663.

Kitamura S, Akutsu M, Okazaki K (2009). Mechanism of action of nitrous oxide gas applied as a polyploidizing agent during meiosis in lilies, Sexual plant reproduction, 22 (1): 9-14.

Lan M, Chen JH, Fei C, Xu QW, Tong ZK, Huang HH, Dong RH, Lou XZ, Lin EP (2020). Induction and characterization of polyploids from seeds of Rhododendron fortunei Lindl, Journal of integrative agriculture, 19 (8): 2016-2026.

Mitrofanova I, Zilbervarg I, Yemets A, Mitrofanova O, Blume YB (2003). The effect of dinitroaniline and phosphorothioamidate herbicides on polyploidisation in vitro of Nepeta plants, Cell biology international, 27 (3): 229-231.

Pintos B, Manzanera JA, Bueno MA (2007). Antimitotic agents increase the production of doubledhaploid embryos from cork oak anther culture, Journal of plant physiology, 164 (12): 1595-1604.

Ramulu KS, Verhoeven H, Dijkhuis P (1991). Mitotic blocking, micronucleation, and chromosome doubling by oryzalin, amiprophos-methyl, and colchicine in potato, Protoplasma, 160 (2-3): 65-71.

Simmonds DH, Newcomb W, Zhao J, Gervais C (2001). Induction of embryogenesis from plant microspores, Google Patents.

Sinski I, Dal Bosco D, Pierozzi NI, Maia JDG, Ritschel PS, Quecini V (2014) Improving in vitro induction of autopolyploidy in grapevine seedless cultivars, Euphytica, 196 (2): 299-311.

Thao, N. T. P., Ureshino, K., Miyajima, I., Ozaki, Y. ve Okubo, H., 2003, Induction of tetraploids in or- namental Alocasia through colchicine and oryzalin treatments, Plant cell, tissue and organ culture, 72 (1), 19-25.

Tosca A, Pandolfi R, Citterio SA, Fasoli A, Sgorbati S (1995). Determination by flow cytometry of the chromosome doubling capacity of colchicine and oryzalin in gynogenetic haploids of Gerbera, Plant cell reports, 14 (7): 455-458.

Touchell DH, Palmer IE, Ranney TG (2020) In vitro Ploidy Manipulation for Crop Improvement, Frontiers in Plant Science, 11, 722.

Väinölä A (2000) Polyploidization and early screening of Rhododendron hybrids, Euphytica, 112 (3), 239244.

Väinölä A, Repo T (2000). Polyploidisation of Rhododendron cultivars in vitro and how it affects cold hardiness, IV International Symposium on In Vitro Culture and Horticultural Breeding 560, 319-322.

Wang LJ, Zhang Q, Cao QZ, Gao X, Jia GX (2020). An efficient method for inducing multiple genotypes of tetraploids Lilium rosthornii Diels, Plant cell, tissue organ culture, 1-12.

Xie X, Agüero C, B, Wang Y, Walker MA. (2015). In vitro induction of tetraploids in Vitis $\times$ Muscadinia hybrids, Plant cell, tissue organ culture, 122 (3), 675-683.

Yang X, Cao Z, An L, Wang Y, Fang X (2006). In vitro tetraploid induction via colchicine treatment from diploid somatic embryos in grapevine (Vitis vinifera L.), Euphytica, 152 (2): 217.

Yemets A, Blume YB (2008). Progress in plant polyploidization based on antimicrotubular drugs, Open Horticulture Journal, 1: 15-20. 